\title{
Posibilidades en el contexto actual
}

\author{
Fabián Lizana, Ignacio Rubio y Rodrigo Hidalgo
}

La situación sanitaria del mundo actual ha abierto una brecha y una inconmensurable posibilidad de comprensión de nuestro espacio geográfico inmediato, los diversos procesos de cuarentena y las medidas de mitigación del avance de la pandemia global del covid-19. Han hecho que nuestro mundo de hace un año atrás sea totalmente diferente y abierto a infinitas posibilidades. Evidentemente nos encontramos en un contexto centrado en la incertidumbre, en donde se debe reorientar el rol de la investigación y el papel que cumple en nuestra sociedad.

Este gran marco lo denominaremos como el de "las posibilidades", un gran vehículo de cambio, trasformación y adaptación a nuevas formas de interpretación de nuestra realidad inmediata, que ha mutado en la medida que la comunidad científica desarrolla una cura para este factor de incertidumbre mundial.

Este contexto antes mencionado, nos ha permitido transitar más de un año por experiencias telemáticas, virtuales, nuevas formas de conectividad e interacción en donde nuestra casa se ha vuelto un espacio contenedor de nuestras experiencias de educación, trabajo e investigación. La vida ha cambiado y lo seguirá haciendo, puesto que existen posibilidades insospechadas dadas la complejidad de la situación sanitaria actual.

En relación con lo anterior, este nuevo numero de la Revista de Geografía Norte grande, intenta entregar a la comunidad hispanoamericana, nuevas una miradas y posibilidades en tiempos complejos como los actuales. Debemos seguir cumpliendo con nuestras autoras(os) su gran esfuerzo, dedicación y su labor investigativa a pesar de las condiciones de este contexto mundial.

\section{El presente número}

Abrimos este número con el profesor Abraham Paulsen, reflexionando sobre el conocimiento geográfico y la forma en que este va construyendo una serie de preconcepciones acerca de las teorías, herramientas metodológicas, estrategias y modelos en el quehacer del geógrafo en formación.

Le sigue el trabajo de Raquel Urroz, que hace un análisis de la literatura geográfica del texto de Manuel Payno, intentando comprender la compleja configuración del paisaje cultural, territorial y geográfico de México en sus primeras décadas de independencia. Para esta interpretación geográfica del paisaje, se utilizan una serie de categorías analíticas de Tuan, permitiendo entender lugares simbólicos, vida cultural y la identidad de las comunidades de este periodo histórico mexicano. 
El siguiente texto es Rodolfo Mardones y Hugo Zunino, que nos habla sobre las comunidades intencionales utópicas (CIU), en donde se analizan una serie de insumos y fuentes directas, las que permiten entender en su forma y contenidos, estructuras representativas de estos grupos. Además de hacer visibles prácticas y discursos desde sus realidades cotidianas, estilos de vida y formas en las cuales habitan sus espacios. Es un enorme esfuerzo por comprender dinámicas contemporáneas de estos grupos y distinguir la diversidad existente dentro de estos agrupamientos.

El texto que sigue es el de Dallys Dantas y Denis Castilho, en el que analiza la importancia logística de estas autopistas y las implicaciones territoriales del modelo de concesión de infraestructura brasileño en el caso de la Región de Goiás, aquí los autores advierten las condiciones financieras de acumulación y el uso corporativo del territorio extendido en la estructura del estado brasileño.

El escrito de Sebastián Rodríguez y Johannes Rehner hace un análisis cuantitativo del empleo en las ciudades intermedias, intentando reconocer en el emprendimiento nuevas pautas territoriales, asociadas con el fomento entregado desde el estado de Chile a esta área económica y sus repercusiones en relación con los incides de desarrollo sostenible urbano del modelo económico chileno.

El siguiente trabajo de José Prada-Trigo, Natalia Aravena y Pablo Barra Vieira, hace un análisis de la sustitución de la "Gran Minería" por el "Sector Inmobiliario", intentando entender procesos espaciales, geográficos e históricos que originan este cambio en el modelo de explotación económico de la zona del Gran Concepción, además de poder entender como los trabajadores se fueron adaptando a estos cambios en los modelos económicos y como se traduce en el desarrollo urbano de la zona.

El texto de Teresa Ropert Lackington, Lucaz González Espinoza, Dariela Sharim Kovalskys y Pablo De Tezanos, hace un estudio cualitativo de cuatro barrios excluidos en Santiago de Chile. Intentando bajo diversas formas metodológicas y procedimentales entender posturas, visiones y modelos de vida que se generan en los barrios excluidos de la (La Legua, José María Caro, Lo Hermida y Los Robles).

El texto de Natalia Lerena Rongvaux y Carolina González Redondo nos habla sobre las trasformaciones de la zona urbana de Buenos Aires, a partir de la transformación de la política de uso de suelo, valorización y estructuras adyacentes en la configuración urbana del sur de la ciudad de Buenos Aires, aquí las autoras evidencian una serie factores en un periodo temporal que va desde el 2003 al 2017, que permitió evidenciar los cambios y continuidades de este gran espacio urbano latinoamericano.

El siguiente texto de Natalia Daniela Soares Da Britto y Oscar Alfredo Sobarzo Miño analizan el programa "CASA MINHA VIDA" de la ciudad brasileña de Pelotas, encontrando una serie comportamientos, modalidades especificas en la producción de viviendas sociales y en la demanda de suelo urbano, amparado por el modelo de financiamiento estatal implementado por el estado brasileño en el último decenio. 
El escrito de Mónica Bustos Peñafiel nos desglosa la política de copropiedad existente en la trayectoria urbana de Chile, intentando entender las complejidades y particularidades de este proceso y diversas tipologías asociadas.

El siguiente trabajo Cinthia Ruiz-López, Antonio Vieyra y Yadira Méndez-Lemus hace un análisis de la segregación espacial en la Zona Metropolitana de Morelia en México, vislumbrando las claves para entender el proceso en esta zona y apreciando características importantes de este proceso en México.

El trabajo de Ricardo Iglesias Pascual y Francisco José Gómez García hace una revisión sobre la dimensión social de la Infraestructura Verde, intentando comprender estructuras similares y distintivas del proceso en diversos espacios.

El siguiente texto de Luis Fernando De Matheus e Silva, nos invita a entender la producción capitalista del espacio en la cordillera austral chilena, con un claro énfasis en las diferentes formas y características en la producción forestal en esta zona del Sur de Chile.

El siguiente artículo de Miguel Puig-Cabrera y Concepción Foronda-Robles nos habla del notorio crecimiento del turismo en los destinos emergentes y problemáticas asociadas con los beneficios, condiciones de vida y la especialización turística, para ello advierte características, ventajas y desventajas de esta actividad turística.

El último texto de Oscar Arley Zuluaga Gómez, Jorge Eduardo Patiño Quinchía y German Mauricio Valencia Hernández habla sobre el cambio climático, específicamente sobre la teledetección y herramientas que posibilitan el análisis de series de tiempo de temperatura superficial e índices de vegetación, a través de herramientas de teledetección.

En las ultimas palabras de esta editorial, agradecemos enormemente a los editores de sección Voltaire Alvarado y Víctor Jiménez, quienes dejan este espacio de difusión para continuar desde otras actividades contribuyendo con nuestra revista de divulgación científica. 
